\title{
Learning Tools and Application for Cognitive Improvement
}

\author{
http://dx.doi.org/10.3991/ijep.v4i3.3665 \\ A. Drigas, M. Karyotaki \\ N.C.S.R. 'Demokritos', Institute of Informatics and Telecommunications, Net Media Lab, Greece
}

\begin{abstract}
Latest trends in learning technologies verify of the fact that they are indispensable for students' cognitive improvement. ICTs in coordination with a concrete pedagogical framework may provide students and teachers flexible, engaging, cost-effective and above all, personalized learning experiences, which focus on the adoption of the $21^{\text {st }}$ century cognitive skills into the actual learning process. Such higher order thinking skills (HOTS) entail critical thinking, problem solving, independent inquiry, creativity, communication, collaboration, digital literacy. Therefore, technologically-supported educational environments aim at self-regulated and inquisitive, constructivist, knowledge building rather than knowledge accumulation.
\end{abstract}

Index Terms-learning technologies, thinking abilities, cognitive skills, learning applications.

\section{INTRODUCTION}

Voogt et al. shed light on the impediments of integrating information and ICTs literacy, also mentioned as " $21^{\text {st }}$ century competencies", into the school practice. Curricular stiffness and obsolete teaching and assessment procedures should be refined in order to upgrade substantially the educational practice. According to the $21^{\text {st }}$ century curriculum, knowledge has a triple meaning. First of all, knowledge should enhance all $21^{\text {st }}$ century competencies, such as information and media literacy skills, communication and collaborative skills, creativity, critical thinking and problem solving skills as well as the way to use them effectively and productively for individual and social development. Furthermore, assessment should be flexible and based on specific and real-life contexts. Thus, $21^{\text {st }}$ century competencies and pedagogy can play an integral role in structuring a trans-disciplinary approach of the school curriculum [1].

Subran delineates the term "higher-order thinking skills" as a set of complex cognitive skills linked to students' learning capacity such as critical thinking, creativity, problem solving and evaluating, the development of which can be accomplished through the integration of ICTs into the school curriculum. Such ICTsbased tasks may require the use of blogs, wikis and social networks [2].

Perrotta contends that substantial innovation in educational settings is hindered by current socio-economic status quo, thus ICTs attribution in assessment may be restricted to mere data-mining processes. More specifically, measurable and standardized performance should be replaced by integrated, interactive, longitudinal, multi-data assessment using digital technologies mean- ingfully and creatively. Nevertheless, the ubiquitous role of technological means in collecting and processing information must be manipulated in a radical way, meaning that educational assessment should overcome intensive, pervasive and quantifiable assessment regimes [3].

According to Psotka, rigorous educational curriculums are an obstacle to the implementation of creative, interactive learning technologies in the classroom, such as game-based learning and virtual reality environments. Reformed pedagogy should set the grounds for stimulating learning experiences, regardless of the student's age or location. Nevertheless, innovative learning environments should be illustrated and assessed both for their efficiency and their pedagogical value [4].

Pepper made an in-depth study on the European assessment of cross-curricular key competences, defined as knowledge, skills and attitudes appropriate to context, in primary and secondary education. There are four distinct approaches of cross-curricular competences assessment. The first refers to explicit assessment of key competences throughout the whole curriculum in comparison to the second that assess key competences only implicitly through subjects or areas. The third approach is related to key competences assessment within subjects and the forth has to do with mere knowledge assessment, rather than competences. Emphasis should be placed on the assessment of students' learning processes in a range of interactive and realistic contexts by deploying digital portfolios and social networking tools [5].

Webb explains the innovative role of ICTs in pedagogical research and practice. Face-to-face or asynchronous learning interactions and assessment are related to students' and teachers' cognitive and ICT skills as well as to the advancements in technology. Research should focus on the enhancement of students' self-regulated, yet supportive and cooperative learning strategies through ICTs [6].

Yan et al. describe an innovative educational technology course for pre-service student teachers, which was designed according to a whole-task model of learning. Whole-task conceptual frameworks aim at teachers' competency through complex, self-directed, interactive and multi-faceted learning environments. Inquiry-based knowledge acquisition, real-life tasks, widespread use of ICTs, a supportive online platform and continuous assessment throughout the course promote students' cognitive and ICTs skills. Students' overall evaluation of the reformed course implied its high quality as well as the importance of emerging technologies in learning and teaching [7].

Duncheon et al. make a thorough analysis of the notion of time throughout the different historical, social, economical and technological settings as well as its importance to educational research. Time theory considers temporal realities as 
PAPER

multi-interpreted constructs related either to the clock time or to time-space ontology. More specifically, ICTs can be a vital counterbalance to the educational inequalities originating in self-identified priorities of time allocation driven by socio-cultural diversities. Indeed, online learning constitutes a more flexible and multitasking learning experience, although time allocation and management when using ICTs remains a controversial issue in student's achievement and academic success [8].

Loh et al. explores on the reform of the Malaysian educational system through the implementation of a holistic and student-centered curriculum, comprising multidimensional educational tools such as the robotic construction kit. It seems that such practical and interdisciplinary works, covering a wide variety of disciplines, such as science, technology, engineering and mathematics train both student's technological literacy and higher-order thinking skills (HOTS). Nevertheless, innovative learning techniques surpass the plentiful intellectual effects as student's psychological benefits are equally important [9].

Mikropoulos et al. present ten-year research findings on the implementation and technological characteristics of virtual reality in the learning process. Educational virtual environments' features are in line with a rather constructivist pedagogical approach, according which interactive 3D multiple, visual-spatial representations mostly through standard interfaces, such as a mouse and a keyboard, conform an authentic, realistic, reflective and possibly collaborative learning experience. Future research should further investigate on virtual reality learning environments in relation to new pedagogical approaches as well as on a more adaptive and personalized educational virtual environment [10].

Sethy argues that e-learning environments and ICTs familiarization, induces inquiry-based, self-directed learning, thus enhancing learner's cognitive skills. Therefore, technology plays a crucial role to effective, knowledge acquisition and structure as long as it follows crystal clear pedagogical principles and objectives. Also, access to technological means and their careful use exceeds social and cultural inequalities, resulting in improved learning and teaching practices [11].

Delfino et al. made a state-of-the-art study on the development of Self-Regulated Learning (SRL) competence through Technology Enhanced Learning Environments (TELEs). Environments, such as the Web, online activities and virtual environments permit the implementation of collaborative or individualized learning experiences, experiential learning approaches as well as self-assessment procedures. All the aforementioned systems and strategies aim to enhance students' autonomous knowledge construction mechanisms. Furthermore, the TELEPEERS, a European project examining the interrelation between self-regulated learning and technology enhanced learning environments, can be expanded as far as its tools, methodology and international adoptability is concerned [12].

\section{StAnd-Alone LEARNING APPLiCATIONS}

Siozos et al. created a Computer-Based Assessment (CBA) tool, called "MyTest" for Tablet PC platform use in secondary education. This innovative assessment application was designed both by students and teachers in a balanced co-participation and it was considered more valuable in terms of utility and ease of use through its Tablet PC version. The features of the assessment application reveal its tailor-made, flexible and qualitative feedback-oriented character. Further research should be done on its successful application under real learning conditions so as to expand its use in secondary level education [13].

Zydney investigated the effectiveness of multiple computer-based tools for complex learning based on the implementation of Cognitive Flexibility Theory. In this study, students' ability to conceptualize the problem's multiple perspectives was high and students' misconceptions were minor, even though the combination tool group was rather ineffective. It seemed that the higher-order thinking tool, a status report, interfered with the organization scaffold, a research plan template. Multiple scaffolding tools can enforce flexible problem understanding if time scheduling and student background are taken into account [14].

Lopez et al. describe the Interactive Graphic Organizers (IGOS) as a virtual training tool originating in Social Semiotics, which supports the interrelation between sign-systems and social reality. More specifically, IGOS sign-systems include cognitively triggering visual schemes with which students interact and formulate new knowledge. IGOS promote cognition through linguistic, non-linguistic elements, conceptual mapping processes and other strategies for word meaning and summarizing in order either to improve students' reading comprehension and text production or to enhance business planning and strategy execution in the business field. Results showed that students validated the beneficiary effects of IGOS implementation in acknowledgement of the latest's, conceptual and structural integrity [15].

Solomonidou presents two representative constructivist, student-centered educational software, which were designed, implemented and evaluated in Greece. The "Interaction between Objects" and "M.A.TH.I.M.A., both based on students' concepts and needs in science teaching. Their respective evaluation process showed students' knowledge improvement, while in the second case students and teachers commented very positively on its applicability. Furthermore, constructivist educational multimedia software use should be extended both through their application in everyday educational contexts and through their free, online availability for all interested parties, thus promoting distance education [16].

Fessakis et al. designed and implemented an exploratory case study addressing the solving of problems in free Logolike programming environments by kindergarten children. Computer programming brought about children's enhanced mathematical, communication and collaboration skills as well as problem solving abilities. Such algorithmic approaches should be thoroughly tested for their learning prospective on a longitudinal and interdisciplinary base [17].

Schmidberger et al. present an interactive exercise software tool for training and testing household technology topics in addition to traditional lectures in the classroom. After its implementation in a Household Technology course of the university of Bonn, university students performed excellent in answering the questions of the test. According to student's self-assesment, the course objectives corresponded perfectly to the content of the test and they were satisfied with staff-student liaison and support, in general. However, extra online exercises should be included in the course in 
PAPER

conjuction with intensive support on account of the teaching staff [18].

\section{INTERNET SUPPORTED LEARNING TOOLS}

Abate Bekele reviewed studies relative to the development of critical thinking and problem solving skills through internet supported learning environments in higher education. Such higher-order thinking skills (HOTS) are generally found to be fairly enhanced by internet supported learning environments, although certain factors, such as students' limited training on the use of cognitive skills, students' insufficient language/writing skills and time management as well as the instructor's limited thinking skills seemed to interfere with the successful implementation of new technological means. Moreover, students' motivation and cultural background in relation to cognitive skills cultivation remains to be addressed in future studies. Contemporary didactic methodology should be revised on account of the technological advances and the emerging learning goals [19].

Callaghan et al. looked into the factors that encourage or interfere with the effective implementation of social networking sites (SNS) in the learning process. Results delineate the immense role of online and offline teacher's presense and support in student's learning experience with social networking sites. As a result, the development of student's higher-order thinking skills (HOTS) were rather ambiguous. However, students' overall motivation, level of engagement and selfdirected learning potential were irrefutably increased. İn future studies, emphasis must be given to the cause-andeffect relationships between quality of interactions and learning in social networking sites environments [20].

Papadakis et al. report the findings of a case study concerning the implementation of an online learning tool, called (LAMS) for the creation of digital lesson plans characterized by their cognitively enhancing contents. This Learning Activity Management System provides teachers the opportunity to design creative, individual or cooperative activities (CS-Wizard) and furthermore to manage their presentation and sharing. Results have shown that computer teachers were able to perform more questions related to higher-order thinking skills (HOTS) even though this application should be further tested on other educational settings and disciplines [21].

Blooma et al. issue micro-collaborations through social media applications dedicated to brief and informal collaborative information seeking services. More specifically, the study attempts to illustrate the sociocognitive processes (SQA) taking place in Social Question Answering (SQA) services in regards to microcollaborative learning practices. Findings suggest that the social and cognitive dimensions of microcollaborations are strongly interelated, which means that micro-collaborations offer simultaneously social acceptance, community coordination, critical thinking and knowledge building. Moreover, microcollaborations as an incentive to collaborative learning, should be firmly grounded on student's increased motivation when incorporated in the educational setting [22].
Curcic made an experimental study on students with reading disabilities and their information problem-solving and management skills development while interacting with the web. Big6 Skills instruction model of information problem solving aimed at improving students' ability to collect and synthesize information for writing expository texts. İts six basic stages include: task definition, information seeking strategies, location and access of information, use, synthesis and evaluation of information. Results showed that writing and organizational quality, text length and navigation were far greater in the treatment group that in the control group. In conclusion, using multiple web resources in an efficient way demand new literacy skills, in which reading, writing and information skills are interconnected. Students with learning disabilities may be benefited from processing digital texts and therefore, electronic text structures should be carefully examined in order to increase their motivation in the learning process [23].

Megalakaki et al. created and explored the learning potential and intercultural essence of an interactive and multidisciplinary, web-based model concerning the e-commerce of several European agricultural products, named AGROweb. This e-shop required the exchange of ideas among secondary school-level children, leading to comprehension and use of information acquired in real problem-based learning environment. In addition, students' increased communication and interaction among themselves and their teacher as well as ICTs' flexibility of use made students' engagement and collaboration even more effective in order to accomplish common goals. Besides students' cognitive gains and adoption of a more European-integrated identity, they were also given the chance to self-reflect on their future careers. Finally, teachers' positive attitude towards ICTs' implementation in the educational process, intensifies the need for prudent integration of technological advances into the school curriculum [24].

Jyothi et al. developed and tested a visualization tool that encodes interaction types in discussion forums. This innovative teaching and learning tool analyzes how learning in forums may have happened by checking participation and interaction patterns. Such "interaction and cognition" feedback is crucial from teachers' and moderators' perspective in order to develop a synergistic, cooperative mode of learning. After testing the aforementioned software, it was found that unmoderated forums were rather ineffective in students' knowledge co-construction. Nevertheless, moderators' prompting and synergistic role in forums was found to be topic or course-related. In conclusion, the system should be refined in terms of its usability, appeal and research capacity so as to be broadly implemented [25].

Rae et al. present a longitudinal study regarding effective teaching of cognitive skills in higher education through a Web-based Personalized System of Instruction (WPSI) including, short video clips, online formative tests and an assessment management system. Empirical evidence proved of its superiority to traditional teaching techniques in students' overall performance, especially for students "at risk" of failing or unmotivated students. Progress should be done in the technological upgrade of ICT delivered materials, such as their usability and applicability so as to enhance students' genuine learning experience in a wide range of courses [26].

Wesiak et al. developed an Integrated Model for Eassessment (IMA) combining multiple forms of assessment, which induce reflective, experiential and socio-cognitive 
PAPER

learning. This model can assess educational, psychological and technological inputs in combination with the Intelligent Web Teacher that provides learners with the most suitable, personalized e-learning experience depending on their cognitive status and learning preferences. The E-assessment system should be refined in regards to its usability by making automatic suggestions for assessment forms related to users' already made selections [27].

\section{ARTIFICIAL INTELLIGENCE-BASED ENVIRONMENTS}

Gaeta et al. present a digital storytelling methodology design and an authoring tool for creating Storytelling Complex Learning Objects (SCLOs) integrated in an advanced e-learning platform, called the Intelligent Web Teacher (IWT). The Storytelling Design Model aims to raise high school students' awareness of safety in a civil emergency context by accomplishing specific learning goals through the development of cognitive abilities. In regards to the authoring tool, it consists of an editor and a player, whose decisions are detrimental to the course of the storyline. Also, through its adaptability strategies it takes into consideration both the player's specific knowledge status (micro-level adaptation) and the player's profiles, cognitive state and learning preferences (macro-level of adaptation). The macroadaptation for learning experience personalization is realized through the Intelligent Web Teacher e-learning platform. The proposed Storytelling Design Model and the authoring tool were found effective for their learning potential, notwithstanding the need for further research on player's emotional and motivational features embedded in the adaptability process [28].

Kronreif developed two robot systems for enabling cognitively and physically impaired children to improve their learning potential and socialization by playing. The first system assists handicapped children's autonomous play with LEGO bricks (PlayROB), whereas the second system aims to facilitate interactive play, either solitarily or collaboratively, on a robot platform with multiple user-centered scenarios depending on children's diverse disabilities (IROMEC). Results showed advancement in children's endurance, concentration and spatial perception but above all, a pleasant and funny way to induce learning and social inclusion [29].

Syufagi et al. introduce the Cognitive Skill Game (CSG), an artificial intelligent agent, which assesses players' cognitive behavior and skills through their interaction with the game. Players' cognitive level classifications came from data gathered by the players' teachers and Learning Vector Quantization (LVQ) method, an Artificial Neural Network, forming three cognitive skill types, high (experts), middle (careful players) and low (trial and error players). Such cognitive skill behavior identification can be part of every serious game so as to maintain players' constant attention and interest [30].

Syufagi et al. made a case study aiming at students' cognitive skills classification during playing the Cognitive Skill Game (CSG). Such cognitive leveling can determine the difficulty of the task in the task level generator and therefore bridge the gap between players' cognitive characteristics and task's cognitive difficulty. Results showed that the majority $(63 \%)$ of the game players exhibited low cognitive skill (trial and error), which means that they had the tendency to make many mistakes, they were low confident and low efficient in solving a problem thoroughly, although they always tried to respond or tried to answer. Players' low efficiency level may depict the game's high level of difficulty. In all cases, CSG feedback should be taken into consideration in any serious game design on the grounds that it will assist both teaching practices and students' assessment. In one word, learning [31].

Di Mascio et al. present a European coordinated, crossdisciplinary, intelligent adaptive learning system, called "The Terence system" aiming at substantially assisting poor text comprehenders to stimulate their reasoning skills for deep text comprehension as well as their educators. It is composed of a set of illustrated stories and interactive question-games, an adaptation engine and the users' interfaces. In conclusion, such eminent interventions may launch more complex and aspiring initiatives [32].

\section{MoBILE LEARNING TECHNOLOGIES}

Terras et al. reveal the psychological background of handheld technology learning as its fruitful use and interaction with learners constitutes a challenging task. Learners' effective mobile learning lays in their engagement and concentration maintenance, which in turn presupposes mobile learning developers' controlling learners' motivation and cognition. More specifically, learners' attention and memory-related capacities as well as their self-regulation ability and digital literacy skills enhancement are related to successful mobile learning. Furthermore, additional obstacles have to be confronted as far as mobile technologymediated knowledge acquisition is concerned, such as digital divides among countries and tailor-made learning environments, based on the interrelatedness between individual's behavior and technological affordances [33].

Moon et al. developed a serious mobile learning game, intended to adapt to a knowledge configuration learning mode. The game was tested for its efficacy in the deployment of higher-order thinking skills (HOTS) while working with others. Learners were divided into two groups: Single player mode and pair-playing mode, with the latest resulting in a "delayed" collaboration framework wherein autonomy and coordination co-exist, hierarchically. Results showed that single players felt they were more capable of applying their cognitive skills to the task, whereas team players were benefited in terms of being occupied with challenging and joyful experiences [34].

Hsu et al. made an exploratory case study of ICTs and mobile device implementation process in three middle school science classrooms. The learning module cultivated new literacies, such as informational and scientific inquiry skills through the integration of cyber databases, a virtual laboratory book template, a spreadsheet and a social networking tool. In general, ICTs and mobile devices promote authentic and student-centered learning experiences in combination with the enhancement of student's cognitive skills, such as identification, retrieval, synthesis, evaluation and communication of the scientific knowledge [35].

Kim et al. introduce "The PSILAN" project, an interactive mobile learning framework for rural or hard-to-reach regions. Pocket-sized mobile learning devices, providing interaction game activities with students' active involvement in their design constitute a joyful, self-reflective and critical mode of building knowledge. In order to evaluate the design 
PAPER

and implementation potential of the "PocketSchool Interactive Learning Ad-hoc Network" project, an application was developed by $5^{\text {th }}$ grade students, requiring critical reasoning and problem-solving skills. Students created and exchanged quizzes in combination with the calculation in real-time of their achievement scores and inquiry ratings. Such framework could well be adopted by under-resourced school settings as its only prerequisite is charging the batteries of the mobile devices. Thus, empirical research is necessary for connecting students' overall positive perceptions towards the project and their academic achievements in the long-run [36].

Kim et al. used a math game-based mobile intervention in order to evaluate underprivileged children's cognitive effects in relation to their group formation, gender and location. Results showed that children went through distinctive stages of cognition while being occupied with the game, which were exploration, recognition, interaction and iteration. Moreover, children's location, gender and group size affected their performance in the game, suggesting that urban boys in flexible groups of three were the most efficient. In the future, research needs to be done on mastering several design features of the mobile game, such as the user's interface and front buttons so as to increase children's intellectual stimulation [37].

Mueller et al. show the immense role of mobile technologies, such as iPods, iPads, BlackBerry devices in diverse educational contexts. Higher education students used a Blackberry device, whereas elementary students used an iPod device both for a whole-year period of time. The studies pointed out that mobile learning is realizable given the appropriate educational settings and strategic use of the aforementioned technologies. The emerging flexible, differentiating and highly engaging learning environments are evident in the elementary students, aiming at self-regulated and inquisitive, constructivist, knowledge building. On the other hand, higher education students gave differentiated meaning in the use of their devices, more embracing the latest's social properties. In conclusion, multi-purpose use of mobile technologies is related to their advanced and diverse mode of integration in education [38].

\section{RESEARCH HIGHLIGHTS}

Learning in the sense of cognitive improvement is a multi-faceted construct related to multiple educational and individual factors. ICTs provide the means for efficient and effective learning through their capacity to offer tailor-made tools and applications that increase students' motivation and enhance their overall cognition.

More specifically, such tools and applications address students' need for knowledge and cognitive improvement through intriguing learning contexts, which combine interactivity, flexibility, applicability and students' self-driven knowledge acquisition. Thus, students are receptors of multiple benefits by the strategic integration of ICTs in education. These benefits point at a constructivistic, knowledge building on account of the students during which, cognitive improvement occurs. Cognitive and meta-cognitive skills improvement entails students' attention, concentration, memory capacity, creativity, critical reasoning, communication, col- laboration, self-regulation, inquiry skills, problem-solving skills and digital literacy skills.

The above skills are improved through several methods adopted by the researchers. Stand-Alone Learning Applications provide students the opportunity to improve their cognition through educational multimedia software, interactive exercise software tools, computer programming and virtual training tools such as the Interactive Graphic Organizers (IGOS).

Internet-Supported Learning Tools encompass microcollaborations through social networking sites environments (SNS), social media applications and the visualization tool for encoding interactions through forum discussions, all aiming at students' socio-cognitive improvement. Online problem-based educational environments, such as the Learning Activity Management System (LAMS) and the AGROweb provide students with cognitively enhancing activities. The Big6 Skills instruction model of information problem-solving in the web focuses on the adoption of digital texts processing for the students with reading disabilities. Also, personalized assessment through the Web-based Personalized System of Instruction (WPSI) and the Integrated Model for E-assessment (IMA), enhances mainly students' self-regulation and inquiry skills.

Artificial intelligence-Based Environments function under a tailor-made rationale, which takes into account cognitive, motivational and emotional features as well as physical impairments in order to increase students' cognition and learning potential. The aforementioned environments include an advanced e-learning platform, called "The Intelligent Web Teacher (IWT)", dedicated to raising students' awareness in case of a civil emergency. Moreover, robotic systems, such as the PlayROB and the IROMEC assist, cognitively and physically impaired children, in training their cognitive and meta-cognitive skills. "The Terence System" is a European, cross-disciplinary project that induces students' deep text comprehension through the enhancement of their reasoning skills. Finally, "The Cognitive Skill Game (CSG)" classifies users in three consecutive cognitive skill levels, providing the grounds for effective serious game design.

Mobile Learning Technologies face up to several challenges concerning their purposeful implementation in the field of cognitive improvement. Mobile devices promote students' inquiry and critical skills through flexible, engaging, cost-effective and multi-purpose applications, such as "The PocketSchool Interactive Learning Ad-hoc Network" in combination with the use of multiple cyber databases and other game-based interventions, regardless of time and space. In this way, educational, technological and societal discrepancies may be substantially dealt with.

\section{CONCLUSIONS}

ICTs can play an eminent role in students' cognitive development as long as they are implemented effectively in teaching and learning practices. ICT tools either for diagnostic or didactic purpose, can develop students' cognitive skills through a well-defined educational and pedagogical framework organized by the teachers. This remains an overwhelming goal as it demands complex thinking skills on account of the teacher. As a result, further research in cognitive tools may lead to students' and teachers' improved cognition in an attempt to develop their inquiry-based, 
PAPER

LEARNING TOOLS AND APPLICATION FOR COGNITIVE IMPROVEMENT

knowledge building skills and competences, eliminating, therefore, learning difficulties.

\section{REFERENCES}

[1] Voogt, J. Erstad, O. Dede, C. and Mishra, P : "Challenges to learning and schooling in the digital networked world of the $21^{\text {st }}$ century", Journal of Computer Assisted Learning, vol. 29, pp. 403-413, (2013). http://dx.doi.org/10.1111/jcal.12029

[2] Subran, D. : "Developing higher-order thinking with ICT", Paper presented at the Biennial Conference of The University of the West Indies Schools of Education, St. Augustine, Trinidad and Tobago, 23-25 April 2013.

[3] Perrotta, C. : "Innovation in technology-enhanced assessement in the UK and the USA: future scenarios and critical considerations", Technology, Pedagogy and Education, (2013).

[4] Psotka, J .: "Educational games and virtual reality as disruptive technologies", Educational Technology \& Society, vol. 16, issue 2, pp. 69-80, (2013).

[5] Pepper, D. : "Assessing Key Competences across the Curriculum - and Europe", European Journal of Education, Vol. 46, number 3, pp. 335-353, (2011). http://dx.doi.org/10.1111/ j.1465-3435.2011.01484.x

[6] Webb, M. : "Changing models for researching pedagogy with information and communications technologies", Journal of Computer Assisted Learning, (2011).

[7] Yan, H. Xiao, Y. and Wang, Q. : "Innovation in the educational technology course for pre-service student teachers in East China Normal University", Australasian Journal of Educational Technology, vol. 28, issue 6, pp. 1074-1081, (2012).

[8] Duncheon, C. J. and Tierney, W. G. : "Changing conceptions of time: Implications for educational research and practice.", Review of Educational Research, vol. 83, issue 2, pp. 236-272, (2013). http://dx.doi.org/10.3102/0034654313478492

[9] Loh, S. C. Loo, C. K. Loh, H. C. and Lim, Y. K. : "Transformative robotic education for the realization of Malaysia National Philosophy of Education”. In FIRA 2013, Springer-Verlag Berlin Heidelberg, pp. 416-426, (2013).

[10] Mikropoulos, T. and Natsis, A. : "Educational virtual environments: A ten-year review of empirical research (1999-2009)", Computers \& Education, vol. 56, pp. 769-780, (2011). http://dx.doi.org/10.1016/j.compedu.2010.10.020

[11] Sethy, S. S. : "Cognitive skills: a modest way of learning through technology", Turkish Online Journal of Distance Education-TOJDE, Vol. 13, Number 3, Article 19, pp. 1302-6488, (2012).

[12] Delfino, M. and Persico, D. : "Unfolding the potential of ICT for SRL Development". In R. Carneiro et al. (Eds), SelfRegulated Learning in Technology Enhanced Learning Environments, pp. 53-74, (2011). http://dx.doi.org/10.1007/978-946091-654-0 4

[13] Siozos, P. Palaigeorgiou, G. Triantafyllakos, G. and Despotakis, T. : "Computer based testing using "digital ink": Participatory design of a Tablet PC based assessment application for secondary education", Computers \& Education, vol. 52, pp. 811-819, (2009). http://dx.doi.org/10.1016/j.compedu.2008. $\underline{12.006}$

[14] Zydney, J. M. : "The effect of multiple scaffolding tools on students' understanding, consideration of different perspectives, and misconceptions of a complex problem, Computers and Education, vol. 54, pp. 360-370, (2010). http://dx.doi.org/10.1016/ j.compedu.2009.08.017

[15] Lopez, M. J. and Ponce, H.R. : "Towards an initial semiotic view of the interactive graphic organizer", ICISO International Conference on Informatics and Semiotics in Organizations, 2010.

[16] Solomonidou, C. : "Constructivist design and evaluation of interactive educational software: a research-based approach and examples", The Journal for Open and Distance Education and Educational Technology, vol. 5, number 1, (2009).

[17] Fessakis, G. Gouli, E. and Mavroudi, E. : "Problem solving by 5-6 years old kindergarten children in a computer programming environment: A case study", Computers \& Education, vol. 63, pp. 87-97, (2013). http://dx.doi.org/10.1016/j.compedu.2012.11.016

[18] Schmidberger, W. and Stamminger, R. : "Application of an interactive exercise tool: student activity, performance and satisfaction in a Household Technology course", International Journal of Consumer Studies, vol. 34, pp. 306-315, (2010). http://dx.doi.org/10.1111/ j.1470-6431.2009.00859.x

[19] Abate Bekele, T. : "Cognitive Skills in Internet-Supported Learning Environments in Higher Education: Research Issues", Scandinavian Journal of Educational Research, vol. 53, number 4, pp. 397-419, (2009). http://dx.doi.org/10.1080/00313830903043182

[20] Callaghan, N. and Bower, M. : "Learning through social networking sites-the critical role of the teacher", Educational Media International, vol. 49, number 1, pp. 1-17, (2012). http://dx.doi.org/10.1080/ 09523987.2012.662621

[21] Papadakis, S. Kordaki, M. and Ghiglione, E. : "Pilot evaluation of LAMS Q\&A CS-Wizard for the improvement of lesson plans and learning design: A case study", European LAMS \& Learning Design Conference, 2010.

[22] Blooma, M. J. Kurian, J. C. Kuan Chua, A. Y. Lian Goh, D. H. and Lien N. H. : "Social question answering: Analyzing knowledge, cognitive processes and social dimensions of micro-collaborations", Computers \& Education, vol. 69, pp. 109-120, (2013). http://dx.doi.org/10.1016/j.compedu.2013.07.006

[23] Curcic, S. : "Adressing the needs of students with learning disabilities during their interaction with the web", Multicultural Education \& Technology Journal, vol. 5, number 2, pp. 151-170, (2011). http://dx.doi.org/10.1108/17504971111142673

[24] Megalakaki, O. Sotiriou, S. Savas, S. and Manoussakis, Y. : "Problem-based educational environments: A case-study in e-commerce and business planning", Electronic Journal of Research in Educational Psychology, vol. 10, issue 1, pp. 423-446, (2012).

[25] Jyothi, S. McAvinia, C. and Keating, J. : "A visualization tool to aid exploration of students' interactions in asynchronous online communication" Computers \& Education, vol. 58, pp. 30-42, (2012). http://dx.doi.org/10.1016/j.compedu.2011.08.026

[26] Rae, A. and Samuels, P. : "Web-based Personalised System of Instruction: An effective approach for diverse cohorts with virtual learning environments?", Computers \& Education, vol. 57, pp. 2423 2431, (2011). http://dx.doi.org/10.1016/j.compedu.2011.06.003

[27] Wesiak, G. Al-Smadi, M. Hofler, M. and Gutl, C. : "Assessment for complex learning resources", iJET, vol. 8, special issue 1: "ICL 2012", pp. 52-61, (2013).

[28] Gaeta, M. Loia, V. Mangione, G. R. Orciuoli, F. Ritrovato, P. and Salerno, S. : "A methodology and an authoring tool for creating Complex Learning Objects to support interactive storytelling", Computers in Human Behavior, vol. 31, pp. 620-637, (2014). http://dx.doi.org/10.1016/j.chb.2013.07.011

[29] Kronreif, G. : "Robot systems for play in education and therapy of disabled children". In I.J. Rudas et al. (Eds), "Towards Intelligent Engineering \& Information Tech", Springer-Verlag Berlin Heidelberg, pp. 221-234, (2009). http://dx.doi.org/10.1007/978-3-642$\underline{03737-516}$

[30] Syufagi, M. Purnomo, M. H. and Hariadi, M. : "Tendency of players is trial and error: Case study of cognitive classification in the cognitive skill games", Journal of Computer Science and Information, vol. 5 , issue 1, pp. 31-39, (2012).

[31] Syufagi, M. A. Hariadi, M. and Mauridhi, H.P. : “ A cognitive skill classification based on multi objective optimization using learning vector quantization for serious games", ITB J. ICT, vol. 5, number 3, pp. 189-206, (2011). http://dx.doi.org/10.5614/itbj.ict.2011.5.3.3

[32] Di Mascio, T. Gennari, R. and Vittorini, P. : "TERENCE project: an adaptive learning system for reasoning about stories with poor comprehenders and their educators". http://www.terenceproject.eu/web/ guest;jsessionid=1DE72AE8F10E56CBA70F6135C6F63207

[33] Terras, M. M. and Ramsay, J. : "The five central psychological challenges facing effective mobile learning", British Journal of Educational Technology, vol. 43, number 5, pp. 820-832, (2012). http://dx.doi.org/10.1111/j.1467-8535.2012.01362.x

[34] Moon, S. Ryu, H.-K. Lee, R.-J. and Song, K.-M. : "Collaborative and cognitive skills development in serious mobile games", Proceedings of the Second International Conference on Information Science and Technology, 2013. 
PAPER

LEARNING TOOLS AND APPLICATION FOR COGNITIVE IMPROVEMENT

[35] Hsu, H.-Y. and Wang S.-K. : "Enhancing scientific inquiry and practicing new literacy skills through ICTs and Mobile Device". In T. Bastiaens \& G. Marks (Eds), Proceedings of World Conference on E-Learning in Corporate, Government, pp. 767777, Healthcare, and Higher Education, 2013.

[36] Kim, P, Seol, S. Karimi, A. Goyal, A. Dodson, B. and Lam, M. : "PocketSchool Interactive Learning Ad-Hoc Network", IEEE Transactions on learning technologies, 2012.

[37] Kim, P. Buckner, E. Kim, H. Makany, T. Taleja, N. and Parikh, V. : "A comparative analysis of a game-based mobile learning model in low-socioeconomic communities of India", International Journal of Educational Development, vol. 32, pp. 329340, (2012). http://dx.doi.org/10.1016/j.ijedudev.2011.05.008

[38] Mueller, J. Wood, E. De Pasquale, D. and Archer, K. "Students learning with mobile technologies in and out of the classroom". In A. Méndez-Vilas (Eds), Education in a techno- logical world: communicating current and emerging research and technological efforts, FORMATEX, pp. 414-420, (2011).

\section{AUTHORS}

A. Drigas is with N.C.S.R. 'Demokritos', Institute of Informatics and Telecommunications, Telecoms Lab - Net Media Lab, Agia Paraskevi, 153 10, Athens, Greece ( email: dr@iit.demokritos.gr)

M. Karyotaki is with N.C.S.R. 'Demokritos', Institute of Informatics and Telecommunications, Telecoms Lab - Net Media Lab, Agia Paraskevi, 153 10, Athens, Greece (e-mail: karyotakimaria@gmail.com)

Submitted 18 March 2014. Published as re-submitted by the authors 13 June 2014 